\title{
Signal Change of Acute Cortical and Juxtacortical Microinfarction on Follow-Up MRI
}

\author{
(D) M. Miyata, (D) S. Kakeda, (D)T. Yoneda, (DS. Ide, (D). Watanabe, (D). Moriya, and (D). Korogi
}

\begin{abstract}
BACKGROUND AND PURPOSE: Although the clinical importance of cortical microinfarcts has become well-recognized recently, the evolution of cortical microinfarcts on MR imaging is not fully understood. The aim of this study was to examine the temporal changes in acute cortical microinfarcts using susceptibility-weighted imaging and conventional MR imaging.
\end{abstract}

MATERIALS AND METHODS: Patients with acute infarcts located in the cortical and/or juxtacortical region measuring $\leq 10 \mathrm{~mm}$ in axial diameter based on diffusion-weighted imaging who had a follow-up 3T MR imaging were retrospectively included in the study. All lesions did not show hypointensity on initial T2*WI. For cortical and/or juxtacortical microinfarcts detected on initial DWI, 2 neuroradiologists evaluated the follow-up MR imaging (T2WI, FLAIR, T2*WI, and SWI) and assessed lesion signal intensities and locations (cortical microinfarcts or microinfarcts with juxtacortical white matter involvement).

RESULTS: On initial DWI, 2 radiologists observed 180 cortical and/or juxtacortical microinfarcts in 35 MR imaging examinations in 25 patients; on follow-up, the neuroradiologists identified 29 cortical microinfarcts (16\%) on T2WI, 9 (5\%) on FLAIR, 4 (2\%) on T2*, and 97 (54\%) on SWI. All cortical microinfarcts detected with any follow-up MR imaging showed hyperintensity on T2WI/FLAIR and/or hypointensity on $\mathrm{T} 2 * \mathrm{WI}$ and SWI.

CONCLUSIONS: SWI revealed conversion (paramagnetic susceptibility changes) of acute cortical microinfarcts, suggesting that a substantial number of cortical microinfarcts may contain hemorrhagic components.

ABBREVIATIONS: $\mathrm{AD}=$ Alzheimer disease; $\mathrm{C} \mathrm{C}$ = cortical and/or juxtacortical; $\mathrm{CMI}=$ cortical microinfarct; $\mathrm{GRE}=$ gradient recalled-echo

A ccumulating evidence suggests that microinfarcts are a common neuropathologic finding in the aging brain. ${ }^{1}$ The prevalence of microinfarcts in patients with probable Alzheimer disease $(\mathrm{AD})$ or vascular dementia is even higher, ${ }^{2,3}$ with a weighted average of $43 \%$ in patients with $\mathrm{AD}{ }^{3}$ Postmortem data from the Adult Changes in Thought (ACT) study, a longitudinal, population-based study of brain aging and dementia, indicated that the most robust pathologic correlate of dementia was an increased number of microinfarcts. ${ }^{4}$ Moreover, Auriel et $\mathrm{al}^{5}$ reported that the chance detection of even 1 or 2 lesions using diffusionweighted imaging suggests an annual incidence of hundreds of new cerebral microinfarcts by a mathematic method for estimat-

Received October 3, 2017; accepted after revision January 31, 2018.

From the Department of Radiology (M.M., S.K., S.I., K.W., J.M., Y.K.), School of Medicine, University of Occupational and Environmental Health, Kitakyushu, Fukuoka, Japan; and Department of Medical Physics in Advanced Biomedical Sciences (T.Y.), Faculty of Life Sciences, Kumamoto University, Kumamoto, Japan.

Please address correspondence to Shingo Kakeda, MD, PhD, 1-1 Iseigaoka, Yahatanishi-ku, Kitakyushu, Fukuoka, 807-8555, Japan; e-mail: kakeda@med.uoeh-u.ac.jp

http://dx.doi.org/10.3174/ajnr.A5606 ing the total number of microinfarcts based on the presence of incidental DWI lesions. Therefore, microinfarct detection is a vital task in MR imaging. Recently, cortical microinfarcts (CMIs) have generated increased interest. ${ }^{6}$ Kövari et $\mathrm{al}^{6}$ assessed the cognitive impact of CMIs, deep white matter and periventricular demyelination, and diffuse and focal gliosis in 43 prospectively evaluated postmortem cases scored as Braak neurofibrillary tangle stage III and found that only CMIs and periventricular demyelination were significantly associated with the Clinical Dementia Rating scale score. ${ }^{6}$

Other previous postmortem studies have also shown an independent relationship between the presence of CMIs and cognitive dysfunction. ${ }^{7,8}$ These findings suggest that CMIs also represent an important mechanistic link between cerebrovascular disease and dementia. Recent studies have shown that it is possible to detect CMIs in vivo using MR imaging. Previous studies have reported that CMIs were detected in $30 \%-40 \%$ of the general older population using 7T MR imaging ${ }^{9,10}$ and in $6 \%$ of older individuals with hypertension using high-resolution $3 \mathrm{~T}$ MR imaging. ${ }^{11}$ However, these studies have limitations because the authors evaluated 
Table 1: Sequence parameters for DWI, TIWI, T2*WI, FLAIR, and 3D multiecho spoiled GRE sequence ${ }^{a}$

\begin{tabular}{lccccc}
\hline & DWI & T2WI & FLAIR & T2*WI & 3D Multiecho Spoiled GRE (SWI) \\
\hline TR (ms) & 6000 & 4000 & 12,000 & 800 & 58.4 \\
Effective TE (ms) & 60 & 85 & 140 & 17 & No. of TEs $^{\text {b }}$ \\
Bandwidth (Hz per pixel) & 1953 & 163 & 98 & 31 & $\pm 62.5^{\circ}$ \\
Flip angle & $90^{\circ}$ & $90^{\circ}$ & $90^{\circ}$ & $30^{\circ}$ & $15^{\circ}$ \\
Section thickness (mm) & 5 & 5 & 5 & 5 & 2 \\
Matrix size & $128 \times 192$ & $512 \times 512$ & $256 \times 224$ & $320 \times 192$ & $320 \times 416$ \\
FOV (mm) & $22 \times 22$ & $22 \times 22$ & $22 \times 22$ & $22 \times 22$ & $22 \times 16.5$ \\
Acquisition time (min) & 0.5 & 3.3 & 3.5 & 2.5 & 7 \\
NEX & 1 & 2 & 1 & 1 & 1 \\
Parallel imaging method (reduction factor) & 2 & 2 & NA & NA & 2 \\
\hline
\end{tabular}

Note:-NA indicates not available.

${ }^{a} \mathrm{~B}$-values of 0 and 1000 via single-shot multislice spin-echo echo-planar imaging for DWI.

${ }^{b}$ Number of echo times, 11; first echo time, 4.5 msec; uniform echo time spacing, 5 msec; repetition time, 58.4 msec

only chronic lesions in patients with no stroke history or months to years after stroke. Because no firm evidence of the nature of CMIs has been confirmed, particularly during the acute phase, a precise definition or finding of CMIs on MR imaging remains elusive. Furthermore, detection criteria for CMIs on MR imaging are not clearly defined, ${ }^{12}$ though accurate diagnosis of CMIs using in vivo MR imaging is desired for appropriate clinical management of patients with dementia.

Many previous MR imaging studies operationally identified CMIs only as cortical hyperintense lesions on T2WI/FLAIR. However, a recent study reported chronic CMIs with hemorrhagic components on histopathologic examination, which were seen as focal accumulations of hemosiderin-containing macrophages accompanied by gliosis and neuronal loss, ${ }^{13}$ suggesting the importance of further evaluating CMIs using MR imaging sequences sensitive to hemorrhagic lesions.

Consequently, we evaluated the imaging evolution of acute CMIs at stroke via MR imaging protocols, including not only T1WI, T2WI, and FLAIR but also T2*WI or susceptibilityweighted imaging. ${ }^{14,15}$ The SWI method, which is more sensitive to magnetic susceptibility, is a useful technique in evaluating patients with cerebrovascular disease. ${ }^{16}$ In stroke imaging units, applications of SWI include the detection of hemorrhagic brain lesions. Moreover, even though 7T MR imaging is more sensitive than $3 \mathrm{~T}$ for CMI detection, ${ }^{9}$ 7T systems are not widely available and can only be used for research. Therefore, the 3T method for the identification of CMIs is preferable for the study of CMIs on a substantially larger scale and in clinical settings, allowing clinically relevant research of CMIs in older individuals and the elucidation of their role in the development of cognitive impairment. In the present study, we identified patients positive for acute CMIs on DWI and evaluated their follow-up MR imaging. The aim of this study was to examine the temporal changes of signal intensities in acute CMIs using SWI and conventional MR imaging.

\section{MATERIALS AND METHODS}

Human experiments were performed in accordance with the guidelines provided and approved by the institutional review board of the University of Occupational and Environmental Health School of Medicine (Kitakyushu, Fukuoka, Japan). Our institutional review board approved this retrospective study, which analyzed existing, de-identified patient data and waived informed consent.
In the present analysis, retrospective review of brain MRIs performed between May 2004 and January 2015 was conducted by 2 radiologists (J.M. and M.M., with 15 and 7 years of experience in neuroradiology, respectively), and they selected patients with acute cortical and/or juxtacortical (CJC) microinfarcts. Acute CJC microinfarcts were defined as small hyperintense lesions on DWI measuring $\leq 10 \mathrm{~mm}$ in the axial diameter and restricted to the cortex or juxta cortex, and the lesions did not show hypointensity on initial T2*WI. In previous studies, the appearances of CMIs on T2WI/FLAIR were operationally defined as cortical lesions of $<5 \mathrm{~mm}$ in greatest dimension. ${ }^{3,9,11,17}$ In general, DWI likely overestimates final infarct size, ${ }^{18,19}$ and an absolute size cutoff of acute CMIs remains controversial. Therefore, in this study, acute CJC microinfarcts were arbitrarily defined as lesions on DWI measuring $\leq 10 \mathrm{~mm}$ in axial diameter. From this cohort, we further selected patients who underwent follow-up brain MR imaging, including the 3D multiecho spoiled gradient recalledecho (GRE) sequence. At our institution, the 3D multiecho spoiled GRE sequence was introduced in January 2015 as part of the routine brain MR imaging evaluation of vascular disease. Therefore, follow-up MR imaging, including the 3D multiecho spoiled GRE sequence, was not a prespecified study end point, and it was only performed as part of routine patient care if clinically indicated for nonspecific symptoms, worsening existing deficits, or recurrent stroke symptoms. The exclusion criteria were as follows: 1) patients with gross abnormalities, such as infarcts, hemorrhages, or brain tumors; and 2) patients with nondiagnostic imaging.

\section{MR Imaging}

All studies were performed on a 3T MR imaging system (Signa Excite 3T; GE Healthcare, Milwaukee, Wisconsin) using a dedicated 8-channel phased array coil (USA Instruments, Aurora, Ohio). All patients underwent 3D multiecho spoiled GRE imaging as well as our standard brain MR imaging protocol, including T1WI, T2WI, FLAIR, T2*WI, and DWI (Table 1). SWI was reconstructed from the 3D multiecho spoiled GRE data. For reconstruction of SWI, a TE of $34.1 \mathrm{~ms}$ was chosen from the 11 echoes.

\section{Image Analysis}

For CJC microinfarcts detected on initial DWI, 2 neuroradiologists (S.I. and S.K., with 12 and 20 years of neuroradiology experience, respectively) evaluated the follow-up MR imaging findings (T2WI/FLAIR, T2*WI, and SWI) and scored the lesions as 


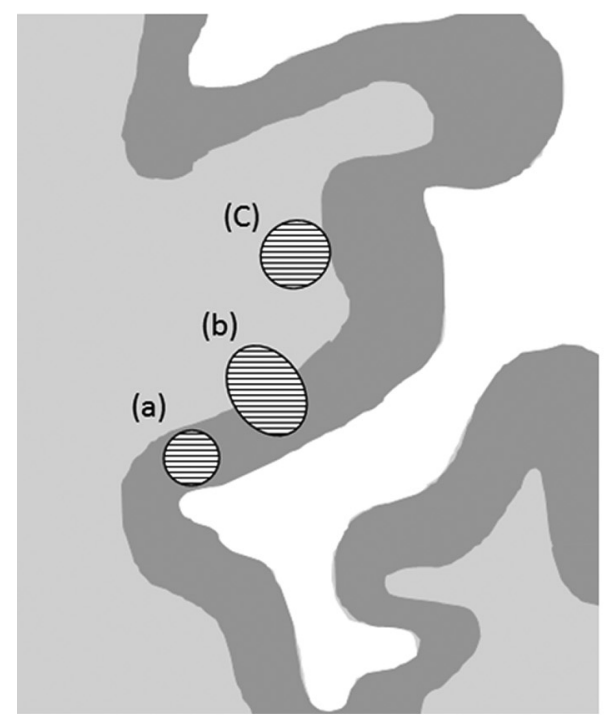

A

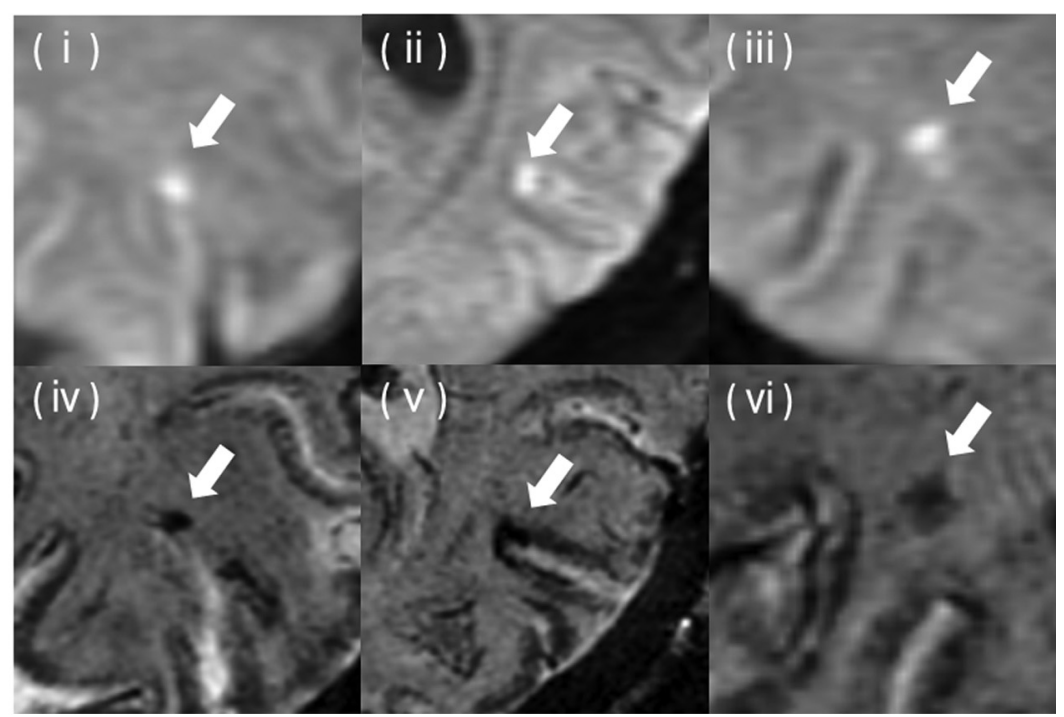

B

FIG 1. A, Schematic drawing illustrating the classification of lesion location. Involvement of the gray matter alone (a), the GM and juxtacortical white matter (b), and the juxtacortical WM alone (c). B, Reference images for the classification of lesion location. Initial DWIs show acute cortical and juxtacortical microinfarcts (i-iii). Each lesion on follow-up SWI is classified as the involvement of the GM alone (a, iv, arrow), GM and juxtacortical WM (b, v, arrow), or juxtacortical WM alone (c, vi, arrow).

either present or absent. They did not evaluate new lesions on follow-up MR imaging. For the reading session, follow-up MR imaging was always evaluated in conjunction with the initial MR imaging. When the result was scored as present, the neuroradiologists were required to evaluate the signal intensity of the lesions and classify the lesion location into the following 3 patterns: involvement of a) the gray matter alone, b) the GM and juxtacortical WM, or c) the juxtacortical WM alone (Fig $1 A) .{ }^{20} \mathrm{We}$ defined the lesions with involvement of the GM [(a) and (b)] as CMIs in this study. Imaging evaluation was performed independently, and final classifications were determined by consensus of the neuroradiologists.

\section{Lesion Detection Rate by the Follow-Up Interval}

For SWI, we evaluated the relationship between the lesion detection rate and the follow-up SWI interval. The follow-up SWI interval was defined as the time between initial MR imaging and follow-up SWI. For the follow-up SWI interval, each lesion was classified into group A ( $<12$ months), group B (12-36 months), or group C ( $>36$ months).

\section{Statistical Analysis}

The total number of lesions was assessed and expressed as mean \pm SD. The mean number of lesions identified on SWI, T2WI, FLAIR, and $\mathrm{T}{ }^{\star} \mathrm{WI}$ was expressed as a percentage of the number of lesions identified on DWI at baseline. Lesion-by-lesion analysis compared the number of lesions per category of the lesion location between T2WI and/or FLAIR and SWI. Regarding the follow-up SWI interval, differences between the lesion-detection rate for each group (group A versus B, group B versus C, and group A versus $\mathrm{C}$ ) were analyzed using the Mann-Whitney $U$ test.

Interobserver reliabilities were calculated as weighted $\kappa$ values. The strength of agreement was considered fair for $\kappa$ values of $0.21-0.40$, moderate for $0.41-0.60$, good for $0.61-0.80$, and excellent for $\geq 0.80$.
Table 2: Patient characteristics

\begin{tabular}{lc}
\hline \multicolumn{1}{c}{ Characteristic } & \\
\hline Sex (female/male ratio) & $8: 17$ \\
Age on follow-up MRI (range) (yr) & $66(39-86)$ \\
MRI examinations (No.) (\%) & \\
1 Time & $19(76)$ \\
2 Times & $3(12)$ \\
3 Times & $2(8)$ \\
4 Times & $1(4)$ \\
Follow-up period (range) (mo) & $33 \pm 35(0.5-142)$ \\
Symptom on admission (No.) (\%) & \\
None & $15(43)$ \\
Pure motor & $16(46)$ \\
Hemiplegia & $2(6)$ \\
Hemianopsia & $2(6)$ \\
Vascular risk factors (No.) (\%) & \\
DM & $8(32)$ \\
HL & $3(12)$ \\
HT & $12(48)$ \\
Smoking & $6(24)$ \\
\hline
\end{tabular}

Note:-DM indicates diabetes mellitus; $\mathrm{HL}$, hyperlipidemia; HT, hypertension.

a Number of initial MRI examination per patients.

\section{RESULTS}

The radiologists selected 28 patients with CJC microinfarcts using the initial DWI, 3 of whom were excluded from the study: 1 patient due to major infarction at follow-up MR imaging and 2 patients because of nondiagnostic imaging due to patient motion artifacts at follow-up T2WI and SWI. Thus, 180 CJC microinfarcts on initial DWI were assessed in 25 patients. Each patient had 1 follow-up MR imaging; no patient had multiple follow-up MRIs. The clinical information is summarized in Table 2.

On follow-up of the 180 lesions, the neuroradiologists identified $52(29 \%)$ on T2WI, $39(22 \%)$ on FLAIR, $4(2 \%)$ on T2*WI, and $101(56 \%)$ on SWI (Table 3). The mean number of lesions was significantly larger with SWI than with the other sequences $(P<.05)$. The neuroradiologists further identified 29 CMIs on T2WI, 9 on FLAIR, 4 on T2*WI, and 87 on SWI (Fig 2). Over- 
Table 3: Follow-up appearances of acute cortical/juxtacortical microinfarcts $(n=180)^{\mathrm{a}}$

\begin{tabular}{lccccc}
\hline & CMIs $^{\text {b }}$ & $\begin{array}{c}\text { T2WI } \\
(\boldsymbol{n}=\mathbf{5 2})\end{array}$ & $\begin{array}{c}\text { FLAIR } \\
(\boldsymbol{n}=\mathbf{3 9})\end{array}$ & $\begin{array}{c}\text { T2*WI } \\
(\boldsymbol{n}=\mathbf{4})\end{array}$ & $\begin{array}{c}\text { SWI } \\
(\boldsymbol{n}=\mathbf{1 0 1})\end{array}$ \\
\hline Mean No. of lesions & & $1.6 \pm 2.8$ & $1.2 \pm 2.1$ & $0.1 \pm 0.4$ & $3.2 \pm 4.6^{\mathrm{C}}$ \\
Lesion locations & (a) & 4 & 3 & 4 & 66 \\
& (b) & 25 & 6 & 0 & 21 \\
& (c) & 23 & 30 & 0 & 14 \\
& (a) + (b) & 29 & 9 & 4 & 87 \\
\hline
\end{tabular}

${ }^{a}$ Numbers in parentheses are total number of lesions.

${ }^{b}$ (a) indicates involvement of the gray matter alone; (b), the GM and juxtacortical white matter; and (c), the juxtacortical WM alone; and $(a)+(b)=$ CMls.

'Significantly different from T2WI, FLAIR, and T2*WI $(P<.05)$.
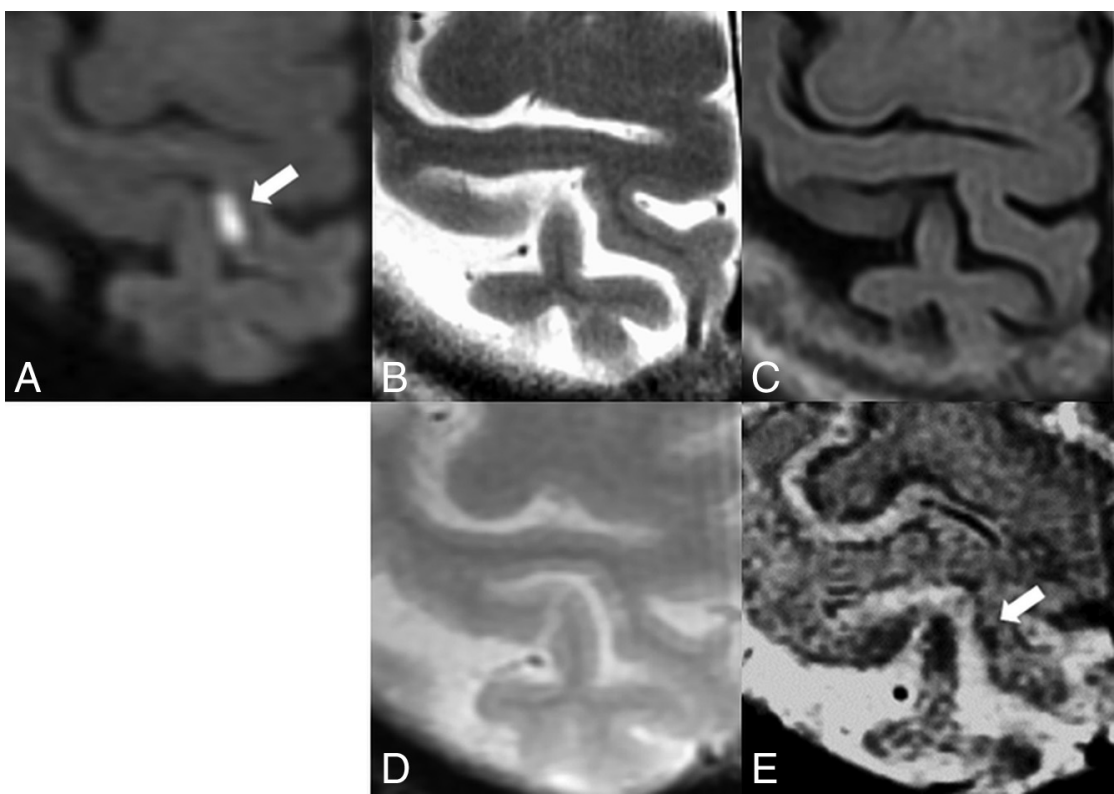

FIG 2. The imaging findings of an 82-year-old woman. The cortical infarct (arrows) shows hyperintensity on the initial DWI $(A)$, hypointensity on the SWI $(E)$, but it is not visible on the follow-up T2WI (B), FLAIR $(C)$, and T2*WI $(D)$.

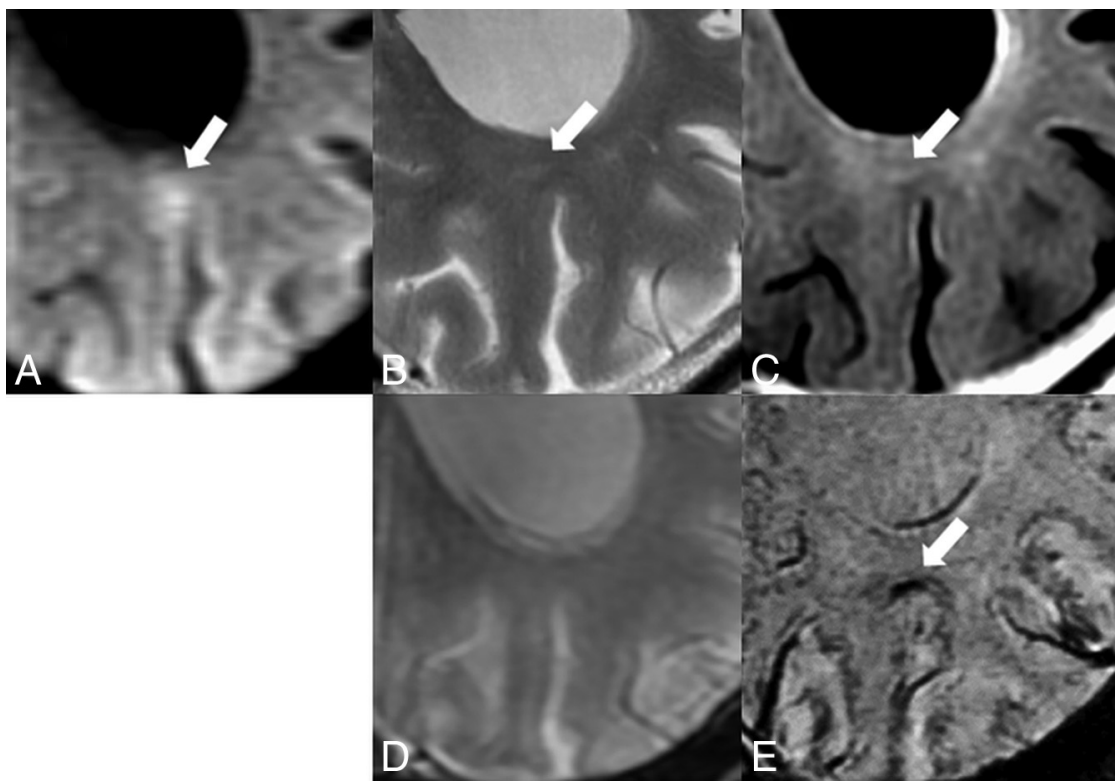

FIG 3. The imaging findings of a 69-year-old man. The acute cortical and juxtacortical microinfarct (arrows) shows hyperintensity on the initial DWI (A). The follow-up T2WI (B) and FLAIR (C) images show juxtacortical white matter hyperintensity (arrows). The hypointensity on SWI (E) was seen only in the gray matter (arrows), but it is not visible on the follow-up T2*WI (D). all, $23(44 \%)$ lesions on T2WI and 30 (77\%) on FLAIR were scored as microinfarcts with sole involvement of the juxtacortical WM (Fig 3).

Lesion-by-lesion analysis (Table 4) demonstrated that of 87 lesions rated as CMIs on SWI, 12 were rated as "juxtacortical WM alone" on T2WI/FLAIR, and 54 lesions were not detected with T2WI/FLAIR. Conversely, 12 of 26 rated as juxtacortical WM alone on T2WI/ FLAIR were rated as CMIs on SWI. Moreover, T2WI/FLAIR identified 17 lesions ( 8 rated as CMIs and 9 as juxtacortical WM alone) that were not seen on SWI.

All of the CMIs detected with any follow-up MR images showed hyperintensity on T2WI/FLAIR and hypointensity on SWI (Fig 3). Regarding the relationship between the lesion-detection rate and the follow-up SWI interval, the lesion-detection rate of group $\mathrm{C}(>36$ months) was significantly lower than those of groups $\mathrm{A}$ ( $<12$ months) and $\mathrm{B}$ (12-36 months) (36\% versus $63 \%$ and 69\%, respectively, $P<.001$ and $P=$ .002) (Table 5). Additionally, there was no significant difference between groups $\mathrm{A}$ and $\mathrm{B}(63 \%$ versus $69 \%, P=.52)$.

The $\kappa$ value for interobserver variability between the 2 radiologists was 0.736 , corresponding to good interobserver agreement.

\section{DISCUSSION}

The main strengths of the present study were that we could precisely pinpoint when the CMIs started and follow their evolution with great precision. CMIs are often counted as chronic infarcts in epidemiologic studies. ${ }^{3,9,11,17}$ In previous studies, CMI appearances were defined as small cortical hyperintense lesions on T2WI/FLAIR and hypointense or isointense on T1WI, with a maximum diameter of $5 \mathrm{~mm}$ and round or elliptic shape. $^{3,9,11,17}$ To our knowledge, this is the first in vivo study reporting the evolution of DWI positive for acute CMIs on SWI or T2*WI. We found that conversion to cortical hypointensities on follow-up SWI occurred in the DWI positive for acute CJC microinfarcts.

Regarding the cortical hypointensities on SWI, the main potential explanation is a hemorrhage (hemosiderin de- 
Table 4: Results of lesion-by-lesion analysis between the T2WI and/or FLAIR and SWI ${ }^{\mathrm{a}}$

\begin{tabular}{|c|c|c|c|}
\hline \multirow[b]{3}{*}{ SWI } & \multicolumn{3}{|c|}{ T2WI and/or FLAIR } \\
\hline & \multicolumn{2}{|c|}{ Positive } & \multirow[b]{2}{*}{$\begin{array}{l}\text { Negative } \\
(n=125)\end{array}$} \\
\hline & $\begin{array}{l}(a)+(b) \\
(n=29)\end{array}$ & $\begin{array}{c}(c) \\
(n=26)\end{array}$ & \\
\hline \multicolumn{4}{|l|}{ Positive } \\
\hline$(\mathrm{a})+(\mathrm{b})(n=87)$ & 21 & 12 & 54 \\
\hline (c) $(n=14)$ & 0 & 5 & 9 \\
\hline \multicolumn{4}{|l|}{ Negative } \\
\hline$(n=79)$ & 8 & 9 & 62 \\
\hline
\end{tabular}

a Numbers in parentheses are total number of lesions. CMIs: (a) indicates involvement of the gray matter alone; (b), the GM and juxtacortical white matter; (c), the juxtacortical WM alone; and $(\mathrm{a})+(\mathrm{b})=$ CMls.

Table 5: Relationship between the lesion detection rate and the follow-up interval on SWI

\begin{tabular}{|c|c|c|c|}
\hline & \multicolumn{3}{|c|}{ Follow-Up SWI Interval ${ }^{a}$} \\
\hline & $\begin{array}{r}\text { Group A } \\
(0-12 \mathrm{mo})\end{array}$ & $\begin{array}{c}\text { Group B } \\
(12-36 \mathrm{mo})\end{array}$ & $\begin{array}{r}\text { Group C } \\
(36+\mathrm{mo})\end{array}$ \\
\hline No. of lesions on initial DWI & 70 & 54 & 56 \\
\hline $\begin{array}{l}\text { No. of stroke events on } \\
\text { initial DWI }\end{array}$ & 13 & 9 & 13 \\
\hline $\begin{array}{l}\text { Lesion-detection rate on } \\
\text { SWI (No.) (\%) }\end{array}$ & $44(63)$ & $37(69)$ & $20(36)$ \\
\hline
\end{tabular}

a The follow-up SWI interval for a lesion was defined as the time between the initial MRI and the follow-up SWI.

position). In a recent extensive review, it was stated that postacute CMIs show as isointense on T2*WI or blood-sensitive scans (eg, gradient-echo or SWI). ${ }^{12}$ However, in another study with 7T postmortem MR imaging and histopathology, 12 CMIs could be classified into different types: chronic gliotic CMIs $(n=5)$, chronic gliotic CMIs with cavitation $(n=3)$ or hemorrhagic components $(n=3)$, and acute CMIs $(n=1) .{ }^{13}$ Evidence of previous hemorrhage in the form of hemosiderin was present in the chronic gliotic CMIs with hemorrhagic components, but unlike microhemorrhages, the presence of such breakdown products of blood was not the primary feature of the lesions. Moreover, chronic gliotic CMIs with hemorrhagic components appeared hypointense on postmortem T2WI, FLAIR, and T2*WI, supporting our hypothesis, though the differences between pathologic subtypes of cerebral microinfarcts have not yet been linked to specific pathogenic mechanisms.

Another possible explanation may be iron deposition sequestered as ferritin in microglia. Microglia appear to have a high ferritin content, ${ }^{21,22}$ and reactive microglia were strongly stained with antiferritin in formalin-fixed, paraffin-embedded sections. ${ }^{23}$ Microglia play an important role in postischemic inflammation. ${ }^{15-17}$ The proliferation of microglia is rapidly induced by cerebral ischemia. ${ }^{18,19}$ Thus, we hypothesized that the signal change of CMI on follow-up SWI may be reflected by ferritin-rich microglial deposition. Moreover, additional factors may lead to an accumulation of other metals within ischemic cells such as copper, zinc, and manganese granules. ${ }^{24,25}$

Several authors have reported that the paramagnetic susceptibility changes can be more conspicuous on SWI than on $\mathrm{T} 2{ }^{\star} \mathrm{WI} .^{26,27}$ In this study, we found conversion to cortical hypointensities on follow-up SWI occurring in 56\% (101/180) of the DWIs positive for acute CMIs. Our results suggest that the true burden of CMIs on imaging may thus have been substantially underestimated in previous studies that only counted the cortical hyperintense lesions on T2WI/FLAIR. On the other hand, we also found CMIs on T2WI/FLAIR that were not visible on SWI, which may correspond to the chronic gliotic CMIs without hemorrhagic components described in the previous histopathologic study. ${ }^{13}$ $\mathrm{T} 2$ lengthening caused by gliosis, edema, and cavitation could mask the decrease in T2 from iron-rich macrophages and cause T2WI/FLAIR images to appear hyperintense instead of hypointense. ${ }^{28}$ Conversely, the paramagnetic field effects of the iron could be enhanced on SWI. Thus, T2WI/FLAIR and SWI provide different information for assessing CMIs; however, this is complementary information. Moreover, our lesion-by-lesion analysis demonstrated that 8 lesions rated as CMIs on SWI were rated as juxtacortical WM alone on T2WI/FLAIR, suggesting that SWI may be more accurate for assessing disease burden, especially GM involvement. In a previous study, phase-weighted MR imaging such as SWI had superior contrast between the GM and the surrounding $\mathrm{WM},{ }^{29,30}$ which may contribute to improved CMI detection. However, CMIs may not be seen on T2WI/FLAIR because they can be obscured from CSF by partial volume effects. Therefore, SWI may provide useful adjunctive information in the evaluation of CMIs.

The follow-up interval for this study was not fixed. The minimum time to follow-up imaging was relatively long (16 days). Therefore, it remains unclear when the signal intensity changes on the phase-weighted images initially appeared. On the other hand, the evaluation of the relationship between the lesion detection rate and the follow-up SWI interval demonstrated that the lesiondetection rate of group $\mathrm{C}$ ( $>36$ months) was significantly lower than those of groups A ( $<12$ months) and B (12-36 months). This result may indicate that some lesions on SWI might not persist for $>3$ years. More recent investigators have identified iron accumulation in multiple sclerosis plaques on Quantitative Susceptibility Mapping and reported that iron accumulation in MS plaques increased rapidly and persisted during its initial few (approximately 4 ) years and gradually dissipated within 4 years. ${ }^{31}$ Regarding the persistence of the iron accumulation, these results are consistent with our study. Therefore, we should be aware of the possibility of an underlying molecular pathway for brain iron metabolism.

There are some limitations associated with our study. First, in our diagnostic work-up, we selected only patients with microinfarcts due to arterioarterial thromboembolism. Some studies assessed patients with cerebral amyloid angiopathy and found an association with the occurrence of microinfarcts. ${ }^{32-34}$ Others found that CMIs were more common in the watershed areas, ${ }^{35,36}$ suggesting that microinfarcts could be related to intermittent focal ischemic episodes because of marginal brain hypoperfusion. In contrast, microinfarcts were also found in brain regions supplied by large cerebral vessels, and several studies found an association with macroscopic infarcts, ${ }^{37-41}$ implying that some microinfarcts could also have an embolic origin. Therefore, our results might reflect only 1 pathologic aspect of CMIs.

Second, the study was limited by its retrospective nature because it was difficult to identify potential associations among data on neuropsychological examinations and MR imaging findings because clinical findings, such as cognitive function, were uncer- 
tain in many cases. Moreover, follow-up MR imaging was performed only as part of routine patient care if clinically indicated for nonspecific symptoms, worsening existing deficits, or recurrent stroke symptoms. Therefore, our results were limited by a lack of follow-up of baseline participants without persisting/new clinical conditions/complaints.

Third, new lesions at follow-up MR imaging were not evaluated because there was no firm evidence of the nature of CMIs and no confirmation during the acute phase on initial DWI. Although on initial and follow-up MR imaging, the lesions were compared very carefully, the possibility of including new lesions in the follow-up MR imaging evaluation could not be excluded completely. Finally, the sample size was relatively small; therefore, larger prospective studies with fixed follow-up time points are required.

\section{CONCLUSIONS}

We evaluated the evolution of DWI positive for acute CMIs on follow-up MR imaging and found conversion (paramagnetic susceptibility change) to cortical hypointensity on SWI, suggesting that many CMIs may contain hemorrhagic components. Our preliminary results suggest that SWI and T2WI/FLAIR provide complementary information, which may be useful in understanding the pathologic processes underlying CMI subtypes. To confirm this, larger prospective studies with predetermined follow-up intervals are warranted.

\section{REFERENCES}

1. Vinters HV, Ellis WG, Zarow C, et al. Neuropathologic substrates of ischemic vascular dementia. J Neuropathol Exp Neurol 2000;59: 931-45 CrossRef Medline

2. Smith EE, Schneider JA, Wardlaw JM, et al. Cerebral microinfarcts: the invisible lesions. Lancet Neurol 2012;11:272-82 CrossRef Medline

3. Brundel M, de Bresser J, van Dillen JJ, et al. Cerebral microinfarcts: a systematic review of neuropathological studies. J Cereb Blood Flow Metab 2012;32:425-36 CrossRef Medline

4. Sonnen JA, Larson EB, Crane PK, et al. Pathological correlates of dementia in a longitudinal, population-based sample of aging. Ann Neurol 2007;62:406-13 CrossRef Medline

5. Auriel E, Westover MB, Bisnchi MT, et al. Estimating total cerebral microinfarct burden from diffusion-weighted imaging. Stroke 2015; 46:2129-35 CrossRef Medline

6. Kövari E, Gold G, Herrmann FR, et al. Cortical microinfarcts and demyelination affect cognition in cases at high risk for dementia. Neurology 2007;68:927-31 CrossRef Medline

7. Gold G, Kovari E, Hof PR, et al. Sorting out the clinical consequences of ischemic lesions in brain aging: a clinicopathological approach. J Neurol Sci 2007;257:17-22 CrossRef Medline

8. Kövari E, Gold G, Herrmann FR, et al. Cortical microinfarcts and demyelination significantly affect cognition in brain aging. Stroke 2004;35:410-14 CrossRef Medline

9. van Veluw SJ, Zwanenburg JJ, Engelen-Lee J, et al. In vivo detection of cerebral cortical microinfarcts with high-resolution 7T MRI. J Cereb Blood Flow Metab 2013;33:322-29 CrossRef Medline

10. Brundel M, Reijmer YD, van Veluw SJ, et al; Utrecht Vascular Cognitive Impairment Study Group. Cerebral microvascular lesions on high-resolution 7-Tesla MRI in patients with type 2 diabetes. Diabetes 2014;63:3523-29 CrossRef Medline

11. van Dalen JW, Scuric EE, van Veluw SJ, et al. Cortical microinfarcts detected in vivo on 3 Tesla MRI clinical and radiological correlates. Stroke 2015;46:255-57 CrossRef Medline

12. van Veluw SJ, Shih AY, Smith EE, et al. Detection, risk factors, and functional consequences of cerebral microinfarcts. Lancet Neurol 2017;16:730-40 CrossRef Medline
13. Van Veluw SJ, Zwanenburg JJ, Rozemuller AJ, et al. The spectrum of MR detectable cortical microinfarcts: a classification study with 7-Tesla postmortem MRI and histopathology. J Cereb Blood Flow Metab 2015;35:676-83 CrossRef Medline

14. Haacke EM, Ayaz M, Khan A, et al. Establishing a baseline phase behavior in magnetic resonance imaging to determine normal vs. abnormal iron content in the brain. J Magn Reson Imaging 2007;26: 256-64 CrossRef Medline

15. Haacke EM, Cheng NY, House MJ, et al. Imaging iron stores in the brain using magnetic resonance imaging. Magn Reson Imaging 2005; 23:1-25 CrossRef Medline

16. Huang $\mathrm{P}$, Chen $\mathrm{CH}$, Lin WC, et al. Clinical applications of susceptibility weighted imaging in patients with major stroke. J Neurol 2012;259:1426-32 CrossRef Medline

17. Jouvent E, Poupon C, Gray F, et al. Intracortical infarcts in small vessel disease: a combined 7-T postmortem MRI and neuropathological case study in cerebral autosomal-dominant arteriopathy with subcortical infarcts and leukoencephalopathy. Stroke 2011;42: e27-30 CrossRef Medline

18. Koch S, McClendon MS, Bhatia R. Imaging evolution of acute lacunar infarction leukoariosis or lacune? Neurology 2011;77:1091-95 CrossRef Medline

19. Potter GM, Doubal FN, Jackson CA, et al. Counting cavitating lacunes underestimates the burden of lacunar infarction. Stroke 2010; 41:267-72 CrossRef Medline

20. Kidd D, Barkhof F, McConnell R, et al. Cortical lesions in multiple sclerosis. Brain 1999;122:17-26 CrossRef Medline

21. Connor J, Boeshore K, Benkovic S, et al. Isoforms of ferritin have a specific cellular distribution in the brain. J Neurosci Res 1994;37: 461-65 CrossRef Medline

22. Han J, Day JR, Connor JR, et al. $\mathbf{H}$ and $\mathbf{L}$ ferritin subunit mRNA expression differs in brains of control and iron-deficient rats. J Nutr 2002;132:2769-74 CrossRef Medline

23. Kaneko Y, Kitamoto T, Tateishi J, et al. Ferritin immunohistochemistry as a marker for microglia. Acta Neuropathol 1989;79:129-36 CrossRef Medline

24. Fujioka M, Taoka T, Matsuo Y, et al. Novel brain ischemic change on MRI: delayed ischemic hyperintensity on T1-weighted images and selective neuronal death in the caudoputamen of rats after brief focal ischemia. Stroke 1999;30:1043-46 CrossRef Medline

25. Siesjö BK. Pathophysiology and treatment of focal cerebral ischemia, part I: pathophysiology. J Neurosurg 1992;77:169-84 CrossRef Medline

26. Tsui YK, Tsai FY, Hasso AN, et al. Susceptibility-weighted imaging for differential diagnosis of cerebral vascular pathology: a pictorial review. J Neurol Sci 2009;287:7-16 CrossRef Medline

27. Haacke EM, DelProposto Z, Chaturvedi S, et al. Imaging cerebral amyloid angiopathy with susceptibility-weighted imaging. AJNR Am J Neuroradiol 2007;28:316-17 Medline

28. Hammond KE, Metcalf M, Carvajal L, et al. Quantitative in vivo magnetic resonance imaging of multiple sclerosis at 7 Tesla with sensitivity to iron. Ann Neurol 2008;64:707-13 CrossRef Medline

29. Futatsuya K, Kakeda S, Yoneda T, et al. Juxtacortical lesions in multiple sclerosis: assessment of gray matter involvement using phase difference-enhanced imaging (PADRE). Magn Reson Med Sci 2016; 15:349-54 CrossRef Medline

30. Kakeda S, Futatsuya K, Ide S, et al. Improved detection of cortical gray matter involvement in multiple sclerosis with quantitative susceptibility mapping. Acad Radiol 2015;22:1427-32 CrossRef Medline

31. Chen W, Gauthier SA, Gupta A, et al. Quantitative susceptibility mapping of multiple sclerosis lesions at various ages. Radiology 2014;271:183-92 CrossRef Medline

32. Olichney JM, Ellis RJ, Katzman R, et al. Types of cerebrovascular lesions associated with severe cerebral amyloid angiopathy in Alzheimer's disease. Ann N Y Acad Sci 1997;826:493-97 CrossRef Medline

33. Soontornniyomkij V, Lynch MD, Mermash S, et al. Cerebral microinfarcts associated with severe cerebral $\boldsymbol{\beta}$-amyloid angiopathy. Brain Pathol 2010;20:459-67 CrossRef Medline 
34. De Reuck J, Deramecourt V, Cordonnier C, et al. The impact of cerebral amyloid angiopathy on the occurrence of cerebrovascular lesions in demented patients with Alzheimer features: a neuropathological study. Eur J Neurol 2011;18:913-18 CrossRef Medline

35. Suter OC, Sunthorn T, Kraftsik R, et al. Cerebral hypoperfusion generates cortical watershed microinfarcts in Alzheimer disease. Stroke 2002;33:1986-92 CrossRef Medline

36. Strozyk D, Dickson DW, Lipton RB, et al. Contribution of vascular pathology to the clinical expression of dementia. Neurobiol Aging 2010;31:1710-20 CrossRef Medline

37. Schneider JA, Arvanitakis Z, Bang W, et al. Mixed brain pathologies account for most dementia cases in community-dwelling older persons. Neurology 2007;69:2197-204 CrossRef Medline
38. Schneider JA, Boyle PA, Arvanitakis Z, et al. Subcortical infarcts, Alzheimer's disease pathology, and memory function in older persons. Ann Neurol 2007;62:59-66 CrossRef Medline

39. Troncoso JC, Zonderman AB, Resnick SM, et al. Effect of infarcts on dementia in the Baltimore longitudinal study of aging. Ann Neurol 2008;64:168-76 CrossRef Medline

40. Longstreth WT Jr, Sonnen JA, Koepsell TD, et al. Associations between microinfarcts and other macroscopic vascular findings on neuropathologic examination in two databases. Alzheimer Dis Assoc Disord 2009;23:291-94 CrossRef Medline

41. Arvanitakis Z, Leurgans SE, Barnes LL, et al. Microinfarct pathology, dementia, and cognitive systems. Stroke 2011;42:722-27 CrossRef Medline 